\title{
REVIEW
}

\section{New aspects of human trichinellosis: the impact of new Trichinella species}

\section{F Bruschi, K D Murrell}

Postgrad Med J 2002;78:15-22

Trichinellosis is a re-emerging zoonosis and more clinical awareness is needed. In particular, the description of new Trichinella species such as $T$ papuae and $T$ murrelli and the occurrence of human cases caused by $T$ pseudospiralis, until very recently thought to occur only in animals, requires changes in our handling of clinical trichinellosis, because existing knowledge is based mostly on cases due to classical $T$ spiralis infection. The aim of the present review is to integrate the experiences derived from different outbreaks around the world, caused by different Trichinella species, in order to provide a more comprehensive approach to diagnosis and treatment.

See end of article for authors' affiliations

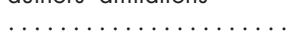

Correspondence to: Dr Fabrizio Bruschi Dipartimento di Patologia Sperimentale, BMIE, Università di Pisa, Via Roma, 55, Pisa, Italy; fbruschi@med.unipi.it

Submitted 22 March 2001 Accepted 24 July 2001
T richinellosis is a parasitic infection caused by a nematode belonging to the genus trichinella. Virtually all mammals are susceptible to infection by one or more species of the genus; however, humans appear to be especially prone to developing clinical disease. Over the past decade, the number of outbreaks around the ing a changing epidemiological paradigm. The severity of the clinical course depends on parasitic factors such as the species involved, the number of living larvae ingested, and host factors such as sex, age, ethnic group, and immune status. It is the purpose of this review to highlight the changes in our understanding of this zoonosis and to suggest some new approaches to the diagnosis and treatment of the infection.

The clinical course of the acute period of infection is characterised by two phases, an enteral phase, in which the parasite alters intestinal function, and a parenteral phase, which is associated with an infiammatory and allergic response to muscle invasion by the larval parasites. Gastrointestinal signs appear first, then fever, myalgia, periorbital oedema, characterise the clinical picture. Death is now rare, owing to improved treatment, but may result from congestive heart failure due to myocarditis, encephalitis, pneumonitis, hypokalaemia, or adrenal gland insufficiency.

A definitive diagnosis may be made when $\mathrm{L}_{1}$ larvae are found in a muscle biopsy; however anamnestic criteria and laboratory findings such as hypereosinophilia, total IgE, and muscle enzyme level increase may help in diagnosis. The use of newer specific serological tests (enzyme linked immunosorbent assay (ELISA) and immunoblot) can improve diagnosis. Treatment is based world appear to have increased markedly, reflect- on anti-inflammatory drugs and antihelminthics such as mebendazole and albendazole; the use of these drugs is now aided by greater clinical experience with trichinellosis associated with the increased number of outbreaks.

The description of new Trichinella species, such as $T$ murrelli and $T$ papuae, as well as the occurrence of outbreaks caused by species not previously recognised as infective for humans, such as $T$ pseudospiralis, now render the clinical picture of trichinellosis potentially more complicated. Clinicians and particularly infectious disease specialists should consider the issues discussed in this review when making a diagnosis and choosing treatment.

\section{SYSTEMATICS}

Trichinellosis results from infection by a parasitic nematode belonging to the genus trichinella. Trichinellosis has been an important, though often unrecognised, disease for thousands of years. Species of trichinella responsible for the infection are widely distributed, including the Arctic, temperate lands, and the tropics. Virtually all mammals are susceptible to infection by one or more species; however, humans appear to be especially prone to developing clinical disease. Infection with wild animal species of trichinella is far more common than is generally recognised. ${ }^{1}$ Human trichinellosis is an important food borne zoonosis because of its epizootic nature and the economic burden associated with preventing its incursion into the human food chain. Its importance in even developed countries is exemplified by the fact that over 20000 cases have occurred in Europe from 1991-2000. ${ }^{1}$

From the time of the discovery of trichinella in 1835 until the middle of the next century, it was commonly assumed that all trichinellosis was caused by a single species, Trichinella spiralis (Owen, 1835). More than a century later, T spiralis had been reported from more than 100 different naturally or experimentally infected mammalian hosts and was believed to be a single species with low host specificity and spread around the world with the movement of domestic swine. Over the last decade, the application of molecular and biochemical methods in conjunction with experimental studies on biology have resulted in the identification of seven Trichinella species, which

Abbreviations: ADCC, antibody dependent cellular cytotoxicity; CPK, creatine phosphokinase; ELISA, enzyme linked immunosorbent assay; IL-5, interleukin-5; LDH, lactate dehydrogenase 
Table 1 Characteristics of the seven identified Trichinella species

\begin{tabular}{|c|c|c|c|c|c|c|}
\hline Trichinella species* & $\begin{array}{l}\text { Muscle } \\
\text { capsule }\end{array}$ & $\begin{array}{l}\text { Infectivity for } \\
\text { pigs }\end{array}$ & $\begin{array}{l}\text { Freeze } \\
\text { resistance }\end{array}$ & $\begin{array}{l}\text { Molecular markers } \\
\text { (PCR) }\end{array}$ & Reported sources & $\begin{array}{l}\text { General geographic } \\
\text { distribution }\end{array}$ \\
\hline$T$ spiralis & + & ++++ & - & $173 \mathrm{bp}$ & Pork; game; horse meat & Cosmopolitan \\
\hline$T$ britovi & + & + & \pm & $127,252 \mathrm{bp}$ & Pork; game; horse meat & Temperate Europe/Asia \\
\hline$T$ pseudospiralis & - & + & - & $300,360 \mathrm{bp}$ & Pork; game & Cosmopolitan \\
\hline$T$ papuae & - & + & - & $240 \mathrm{bp}$ & Pork; game & Papua New Guinea \\
\hline$T$ nativa & + & - & +++ & $127 \mathrm{bp}$ & Game & Arctic/subarctic \\
\hline$T$ nelsoni & + & + & - & $155,404 \mathrm{bp}$ & Game & Africa (south of Sahara) \\
\hline$T$ murrelli & + & - & - & $127,361 \mathrm{bp}$ & Game; horse meat & North America \\
\hline
\end{tabular}

have distinct epidemiological and geographical distributions (table 1). Although the species are difficult to differentiate morphologically, they can be typed with molecular and certain biological characters. ${ }^{2}$

\section{LIFE CYCLE}

All stages in the life cycle of trichinella occur in individual mammalian hosts. When skeletal muscle containing the infective larvae is ingested by another mammal, the larvae are released by the action of gastric fluids and pass into the small intestine. There, the parasites invade the small intestine epithelial wall, and moult four times before becoming sexually mature. After copulation, the females begin to expel newborn larvae about six or seven days after infection. This process continues for the life of the female. Although it is generally believed that the adult worms may persist in the intestine for only several weeks, there is evidence that they may survive for much longer periods, especially if the host's immune system is compromised. Most of the newborn larvae penetrate into the submucosa and are carried in the circulatory system to various organs, including the myocardium, brain, lungs, retina, lymph nodes, pancreas, and cerebrospinal fluid. However, only the larvae that invade the skeletal muscle survive. In most species they gradually encyst and develop into the infective stage about 21 to 30 days after infection (fig lA). However, in two species, $T$ pseudospiralis and T papuae, the muscle larvae do not induce the formation of a cyst or capsule (fig 1B). Larval infectivity can be retained for many years, depending on the species of host. The larvae appear to be non-pathogenic for the natural hosts (excluding humans) unless very large numbers are involved.

\section{EPIDEMIOLOGY}

The most salient feature of this parasite's epidemiology is its obligatory transmission by ingestion of meat. A second cardinal feature is its existence in two normally separate ecological systems, the sylvatic and the domestic. ${ }^{3}$ In certain circumstances, the two biotopes are linked through man's activities, resulting in the exposure of humans to Trichinella species normally confined to sylvatic animals. The species most frequently associated with human infection is $T$ spiralis, the species that is normally found in domestic pigs. The domestic cycle of $T$ spiralis involves a complex set of potential routes. Transmission on a farm may result from predation on or scavenging other animals (for example, rodents), hog cannibalism, and the feeding of uncooked meat scraps. Until recently, outbreaks predominantly resulted from consumption of $T$ spiralis infected pork in local, single source outbreaks; however, increasingly, the mass marketing of meat can disseminate the parasite throughout a large population. Also of importance is the growing proportion of outbreaks caused by sylvatic Trichinella species, either directly through game meat or through spillover to domestic animals. Recent reports also indicate that infected herbivores (horses, sheep, goats, and cattle) have been the source of outbreaks, a new variation on the traditional model of trichinellosis epidemiology. Examples are recent human infections attributed to $T$ pseudospiralis in New Zealand in 1994, recently in Thailand where 59 people were infected by pig meat, and in France where an outbreak from wild boar meat occurred in 1999.

In countries where meat inspection for trichinella is not mandatory, ${ }^{4}$ other strategies for reducing consumer risk are followed. In the United States, for example, consumers are advised on proper meat handling procedures (for example, cooking, freezing, curing) for killing any trichinella present. Cooking to an internal temperature of $60^{\circ} \mathrm{C}$ for at least one minute is advised. Consumers are also urged to freeze pork at either $-15^{\circ} \mathrm{C}$ for 20 days, $-23^{\circ} \mathrm{C}$ for 10 days, or $-30^{\circ} \mathrm{C}$ for six days if the meat is less than $15 \mathrm{~cm}$ thick. These temperatures may not be adequate, however, for wild game meat infected with species such as $T$ nativa, which is freeze resistant. The curing of pork sufficient to kill trichinella is difficult to standardise. Commercial production of ready-to-eat pork products is carried out under scrutiny of regulatory agencies to ensure food safety.
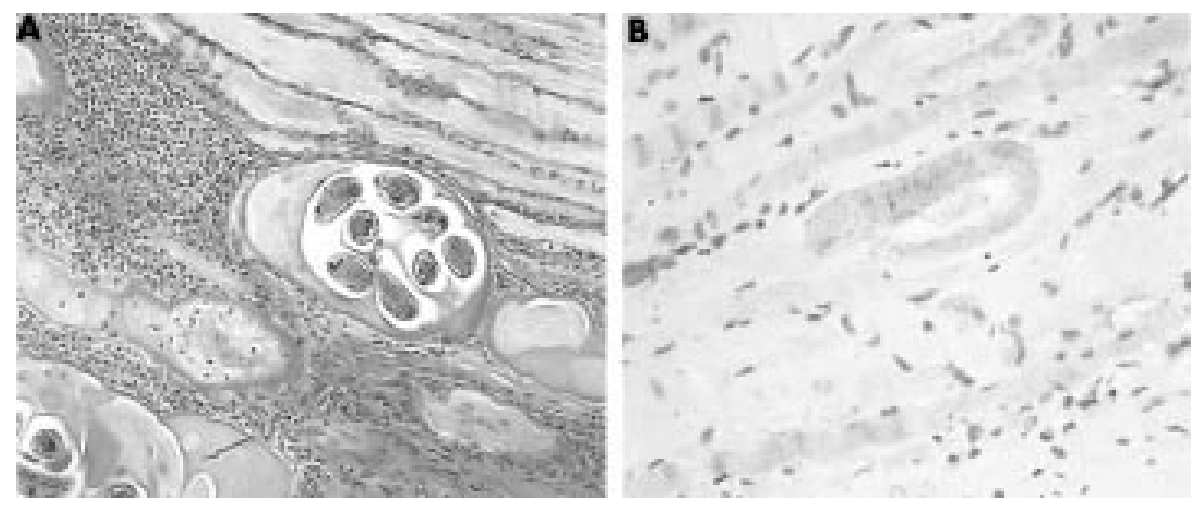

Figure 1 Histological appearance of Trichinella species $L_{1}$ larvae located in diaphragms of mice experimentally infected. (A) Sample from a mouse infected with $T$ britovi. Note around the nurse cell numerous inflammatory cells (trichrome stain; original magnification $\times 200$ ). (B) Sample from a mouse infected with $T$ pseudospiralis. Only few inflammatory cells are present around the $\mathrm{L}_{1}$ larva (haematoxylin and eosin; original magnification $\times 200$ ) 


\section{PATHOGENESIS}

\section{Enteral phase}

At intestinal level, the mechanisms regulating the immune response to a primary infection in humans, are not clear. The prolonged diarrhoea observed in outbreaks in the Canadian Arctic $^{56}$ suggests adult worms persist in the intestine of people with frequent exposure to infection. This could be due to a possible downregulation of the intestinal immune response or of gut physiology, or to a premunition state.

Experimental studies in rodents infected with $T$ spiralis have shown that the early phase of helminthic infection, when the the parasite is present in the gastrointestinl tract, induces a type I hypersensitivity reaction, leading to increased levels of mast cells, eosinophils, and parasite specific IgE production. This isotype has a protective role in intestinal immunity in rodents. ${ }^{7}$ Very recently, it was shown that the mucosal mast cell protease- 1 plays a crucial part in determining the expulsion of trichinella adult worms, in fact knock-out mice for the corresponding gene significantly delayed expulsion and increased the number of encysted lavae, compared with wild type animals. ${ }^{8}$

In the jejunum of patients infected with $T$ spiralis an increased number of mucosal mast cells occurs. ${ }^{9}$

Diarrhoea during infection is a consequence of a physiological process induced by the parasite, resulting in active secretion of ions and water, as occurs with Vibrio cholerae. ${ }^{10}$

\section{Parenteral phase}

This is associated with inflammatory and allergic responses caused by the invasion of the muscles by the migrating larvae. This invasion can damage the muscle cells directly, or indirectly stimulating the infiltration of inflammatory cells, primarily eosinophils. A correlation between the eosinophil levels and serum muscle enzymes has been observed in trichinellosis patients, suggesting that muscle damage may be mediated by these granulocytes. ${ }^{11}$

The involvement of the central nervous system during infection, the so-called neurotrichinosis, arises mainly from vascular perturbations, for example, vasculitis and granulomatous inflammatory reactions surrounding invading larvae. The newborn larvae tend to wander, causing damage before re-entering the bloodstream, or may remain trapped to be later destroyed by the provoked granulomatous reaction. ${ }^{12}$ Neural cells may also be damaged by eosinophil degranulation products such as eosinophil derived neurotoxin and major basic protein. $^{13}{ }^{14}$

Myocarditis results initially from muscle cell invasion by the migrating larvae, then from immunopathological processes such as eosinophil infiltration and mast cell degranulation. ${ }^{15}$

\section{Immunological aspects}

The mechanisms responsible for the pronounced eosinophilia, frequently observed in trichinellosis, are not well understood. Differentiating factors specific for eosinophils such as interleukin-5 (IL-5), ${ }^{16-18}$ produced by the Th2 subset of CD4+ $\mathrm{T}$ cells, may be involved. Recently, in experimental infections, it has been shown that this cytokine could act by protecting cells from the apoptotic death which normally affects eosinophils. ${ }^{19}$ The role of IgE in inducing the eosinophilia is controversial. ${ }^{201}$ Eosinophils are cytotoxic for newborn larvae in both animal ${ }^{22}{ }^{23}$ (fig 2) and human antibody dependent cellular cytotoxicity (ADCC) "in vitro" reactions, ${ }^{24} 25$ by releasing the major basic protein, ${ }^{26}$ peroxidase, ${ }^{27}$ or reactive oxygen species.$^{28}$ However, their actual role "in vivo" is not clear. Suppression of eosinophilia by an IL-5 specific monoclonal antibody "in vivo" does not modify either primary or secondary parasitic infections in mice. ${ }^{29}$ Knock-out ${ }^{30}$ and transgenic ${ }^{31}$ mice for IL-5 have the same parasitic burden as controls, however in the former case the cytokine seems to promote expulsion and muscle hypercontractility.

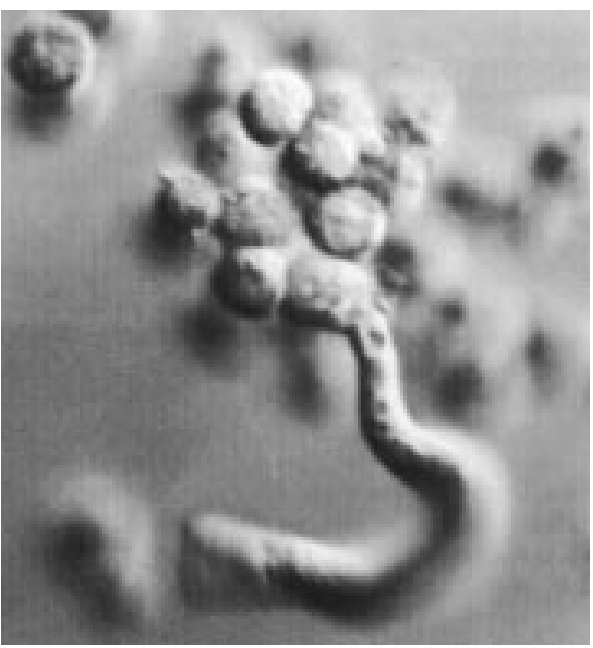

Figure $2 T$ spiralis newborn larva alive within peritoneal cells, from normal mice, adhering to the parasitic cuticle, in the presence of hyperimmune serum, after six hours of incubation (interferential phase contrast microscopy, 1/48 sec; original magnification $x$ 1000; from Bruschi $F$, et al ${ }^{101}$ with permission).

Nevertheless, a very recent study has shown that IL-5 deficient mice show an impaired defence against a secondary $T$ spiralis infection, at intestinal level, suggesting a relevant role of this cytokine in challenge infections. ${ }^{32}$

The few data on the non-encapsulated species are from experimental infections with $T$ pseudospiralis. This species appears to be less virulent and pathogenic than $T$ spiralis, generating less inflammation at intestinal and muscle level..$^{33}$ This is probably due to the ability of this species to induce elevations in host plasma corticosterone. ${ }^{34}$

\section{CLINICAL MANIFESTATIONS}

The severity of the clinical course depends on the species involved. For example, in the recent outbreak in Thailand caused by $T$ pseudospiralis, the clinical course in patients was unusually prolonged. ${ }^{35}$ Other factors affecting the clinical course are the number of living larvae ingested, and sex, age, and ethnic group of the host. ${ }^{36}$ Immune status also plays an important part as shown in humans, ${ }^{37}$ and in experimental infections in which steroids and immunosuppressive treatments prolong the survival of adult intestinal worms. ${ }^{38}$ Furthermore, the prolonged diarrhoea in the absence of myalgia, reported in elderly Inuit people, may be due to previously acquired immunity against the enteral and parenteral stages of the parasite. ${ }^{56}$

The disease incubation period ranges from seven to 30 days, depending on the severity of infection. When the course of infection is more severe, the incubation period is brief, although death may also occur in association with a longer incubation period. ${ }^{36}$

The clinical course of the acute period of infection is characterised by two phases, an enteral phase, in which the parasite alters intestinal function, and a parenteral phase, which is associated with an infiammatory and allergic response to muscle invasion by the larval parasites. ${ }^{39}$ The first gastrointestinal signs result from mucosal invasion by the $\mathrm{L}_{1}$ (stage 1) (ingested) larvae. These signs typically last two to seven days, but may persist for weeks. Subsequently, the so called trichinellotic syndrome or general trichinellosis syndrome, begins (see below). However, the acute phase, lasting one to eight weeks, is commonly asymptomatic, especially when the number of larvae ingested is low.

The clinical course of enteral infection may be abortive (symptomatology not complete), mild (complete even if mild), moderate, and severe (frequently associated with 
complications)..$^{40}$ Malaise, anorexia, nausea, vomiting, abdominal pain, fever, diarrhoea, or constipation may occur. Diarrhoea is more persistent than vomiting, lasting up to three months, and, when excessive, causes dehydration; this, together with enteritis, is an occasional cause of death. Variations in this pattern occur, particularly in relation to a possible premunition state, as already mentioned. ${ }^{56}$

Muscles are mainly affected during the parenteral phase, including the myocardium. The central nervous system, lungs, kidney, and skin may be affected. The trichinellotic syndrome is characterised by facial oedema, muscle pain and swelling, weakness, and frequently fever; anorexia, headache, conjunctivitis, and urticaria occur less frequently. ${ }^{3640}$ Fever, usually remittent, generally begins at two weeks, and peaks after four weeks, with values up to $40-41^{\circ} \mathrm{C}$ in severe cases. Despite fever, patients may appear in good condition. Ocular signs (oedema of the eyelids, chemosis, conjunctivitis, conjuctival haemorrhages, disturbed vision, and ocular pain) at this time may help in diagnosis. Periorbital oedema is peculiar to trichinellosis, ranging from $17 \%$ to $100 \%$ of patients in over 2000 trichinellosis cases reviewed. This oedema is probably the result of an allergic response. ${ }^{41}$

The entire face may also be involved, giving patients a characteristic aspect, often rendering them unrecognisable. The frequency of facial oedema during infections caused by T murrelli was lower than that observed in $T$ spiralis human infections that occurred in France in the same year. ${ }^{42}$ At this time the muscles of the rest of the body usually become painful. Extraocular muscles, masseters, tongue and larynx muscles, diaphragm, neck muscles, and intercostal muscles are most frequently infected.

The pain may be so severe as to limit function of the arms and legs, inhibiting walking, speaking, moving the tongue, breathing, and swallowing. Weakness is also a consequence of the muscle involvement. The muscles become stiff, hard, and oedematous; the oedema may be so intense as to simulate hypertrophy. ${ }^{43}$ Oedema lasts one or two weeks and disappears with increased diuresis. Myalgia and asthenia lasted more than four months in the Thailand outbreak caused by $T$ pseudospiralis. ${ }^{35}$

Gastrointestinal symptoms such as diarrhoea may also extend into this parenteral phase. ${ }^{36}$ Dyspnoea (even ventilatory failure),${ }^{44}$ coughing, and hoarseness may also be present. Dyspnoea is caused primarly by parasite invasion and consequent inflammations of respiratory muscles such as the diaphragm. Bronchopneumonia and infarction may also be involved. In the first days of treatment with albendazole in a $T$ pseudospiralis outbreak difficulty of respiration was observed, probably due to the release of toxic products from damaged parasites. ${ }^{35}$ The cough begins in correspondence with the passage of the larvae through the capillary bed of the lungs, about one week after infection. ${ }^{45}$

Neurological manifestations, more common in severe infections, occur in $10 \%$ to $24 \%$ of cases. ${ }^{46}{ }^{47}$ In 55 patients affected by neurotrichinosis, meningoencephalitic signs were the most frequently observed clinical signs (96\%), followed by focal paralysis or paresis (73\%), and delirium (71\%); psychosis was also reported. ${ }^{47}$

Headache is very common in trichinellosis, and is exacerbated by movements of the head. Mortality due to central nervous system involvement is now less frequent because of the improved treatment.

Myocarditis is the most frequent cardiovascular complication, leading sometimes to heart failure or bronchopneumonia; in some cases death occurs between the fourth and the eigth week of infection, although sudden death may occur even earlier. ${ }^{36}$ Arrhythmias, secondary to myocarditis, may also occur. In one case it was necessary to use a pacemaker for one year to maintain normal cardiac rhythm. ${ }^{44}$ Electrocardiographic alterations may be present from the second week and may persist up to the third or fourth week. The principal alterations are premature contractions, prolongation of the $\mathrm{P}-\mathrm{R}$ interval, small QRS complexes with intraventricular block, and flattening or inversion of the $\mathrm{T}$ waves, especially lead II and precordial leads.

Blood pressure may be low during the early phase of infection and may also remain low during convalescence. Oedema due to heart failure has been observed, generally later when oedema due to myositis has almost disappeared. Less frequent vascular signs are epistaxis, haemoptysis, haemorrhages from the bowel, thrombosis of the femoral or pulmonary artery, and embolism. In one fatal case, the arterioles of different organs were affected by disseminated intravascular coagulation with platelet fibrin thrombi. ${ }^{48}$ Less frequent are petechial haemorrhages, mainly subungual, and roseola and maculopapular exanthems, resembling measles. ${ }^{45}$

After the acute period, convalescence follows (lasting from months to years), usually with a complete recovery. Over the ensuing years, muscle larvae are slowly destroyed, followed by calcification. ${ }^{49}$ This may occur earlier in infections with sylvatic species. ${ }^{50}$

The existence of chronic trichinellosis ${ }^{51}$ or as some investigators prefer, "persisting sequelae" myalgia, early fatigability, ocular signs, and headache for decades), is somewhat controversial and requires investigations. Some recent studies have confirmed the occurrence of these sequelae for periods up to 10 years after clinical recovery. ${ }^{52-54}$

Although death is now rare in trichinellosis, owing to improved treatment, it may result from congestive heart failure due to myocarditis, encephalitis, pneumonitis, hypokalaemia, or adrenal gland insufficiency. ${ }^{36}$ In the United States, during the period 1991-96, in 230 cases reported to the Centers for Disease Control in Atlanta, only three deaths occurred. ${ }^{55}$ During the outbreak caused by $T$ pseudospiralis in Thailand there was one fatality in 59 patients, due probably to the very large amount of parasite-infected meat ingested. ${ }^{35}$ During a horsemeat outbreak in France, caused by the newly described T murrelli, a $0.46 \%$ mortality rate was observed. ${ }^{42}$ No deaths were reported in outbreaks caused by $T$ britovi.

\section{DIAGNOSIS}

Is trichinellosis a low prevalence disease or is it frequently misdiagnosed? The answer is not obvious.

When the infection occurs in epizootic or outbreak form its diagnosis is easier. It is difficult in low level or sporadic infections, because the clinical picture is often common to many other diseases, infectious or not, such as typhoid fever, influenza, chronic fatigue syndrome, myositis during HIV infection, polyarteritis nodosa, and eosinophilic leukaemia. This makes it is necessary to carry out a differential diagnosis.

Special care must be taken when developing clinical histories; particular attention should be paid to eating habits during the weeks before the onset of symptoms. Exposure to infected meat (raw or incompletely cooked), the presence of gastroenteritis, myalgia, facial oedema, subungual or conjunctival haemorrhages, and an increase in eosinophil levels should suggest trichinellosis. ${ }^{36}$ Electromyography may help in the diagnosis of moderate and severe infections during the acute period, even if the muscle changes are not pathognomonic. With clinical improvement, electromyography changes generally disappear within two to three months, ${ }^{56}$ although these alterations may persist for one to eight years. ${ }^{57}$

\section{Muscle biopsy}

A definitive diagnosis may be made when $\mathrm{L}_{1}$ larvae are found in a muscle biopsy, generally performed in the deltoid muscle; although in humans other muscles are more infected, the deltoid is preferred because it is more accessible. ${ }^{58}$ Muscle biopsy is recommended only in rare and difficult cases, particularly when serology is not clear. A negative result, however, does not 
Table 2 Laboratory findings in human trichinellosis

\begin{tabular}{|c|c|c|c|c|c|}
\hline Constant & Exceptions & Frequent & When & Rare & When \\
\hline \multirow[t]{3}{*}{$\begin{array}{l}\text { Hypereosinophilia* } \\
\text { (up to } 19000 / \mu \text { ) }\end{array}$} & $\begin{array}{l}\text { Very severe infections; } \\
\text { coinfections with bacteria }\end{array}$ & & & Eosinopenia & After steroid therapy \\
\hline & & $\begin{array}{l}\text { Leucocytosis, up to } 24000 / \mu \text { l } \\
\text { CPK (up to } 17000 \text { units/I), } \\
\text { LDH, aldolase level increase } \\
\text { Total IgE level increase }\end{array}$ & $\begin{array}{l}\text { Early in severe infections } \\
\text { Parenteral phase with } \\
\text { muscle damage } \\
\text { Parenteral phase mainly }\end{array}$ & & \\
\hline & & & & $\begin{array}{l}\text { Hypoalbuminaemia } \\
\text { (down to } 25 \mathrm{~g} / \mathrm{l} \text { ) }\end{array}$ & $\begin{array}{l}\text { Severe infections or } \\
\text { infections caused by } \\
T \text { pseudospiralis }\end{array}$ \\
\hline
\end{tabular}

exclude the presence of a low level infection..$^{59}$ Artificial digestion ( $1 \%$ pepsin-hydrochloric acid) of a muscle sample is more sensitive than direct microscopic observation of the tissue specimen. Importantly, the isolation from muscle cannot be carried out before 17 to 21 days of infection because larvae are not yet resistant to digestion. ${ }^{60}$ When $T$ pseudospiralis or $T$ papuae (non-encapsulating species) are suspected as aetiological agents, digestion methods must be performed with care. ${ }^{61} \mathrm{~A}$ muscle biopsy is useful, however, not only for making a diagnosis but also to collect important information on the level of infection, the pathological changes in the muscle tissue, the infection time, and for genetic typing (by random amplified polymorphic DNA analysis of the parasite) ${ }^{62}$ This is important when the source of infection is unknown or no longer available. Molecular techniques allowed for the first time the identification of $T$ pseudospiralis in a human trichinellosis case in Tasmania. ${ }^{63}$ All such information is useful for the choice of future therapeutic strategies. ${ }^{36}$

Histological examinations may reveal modifications of skeletal muscles, including basophilic degeneration of the fibres, fatty metamorphosis, hyaline or hydropic degeneration, or both, and interstitial inflammation; sometimes it is possible to observe dead non-encapsulated parasites. ${ }^{58}$ Increased vascularity, small haemorrhages, accumulation of inflammatory cells, mainly eosinophils, among the muscle cells (myositis) are also visible. ${ }^{64} 65$

Encapsulation of the parasite, with the exception of $T$ pseudospiralis and T papuae, begins at about two weeks and is usually completed at five weeks of infection, ${ }^{58}$ depending on the Trichinella species involved..$^{50}$ In humans, calcification begins about five months after infection and is usually completed after 18 months. ${ }^{58}$

As already mentioned, the diagnosis of trichinellosis is difficult in sporadic cases, but is even more difficult when central nervous system involvement is present. Neurotrichinosis is sometimes accompanied by multifocal central nervous system lesions, nodular or ring-like, and showing frequently contrast enhancement. ${ }^{14}{ }^{66}$ However, computed tomography images of the brain have been normal also in the presence of neurological manifestations. ${ }^{66} 67$

\section{LABORATORY FINDINGS}

\section{Non-specific findings}

The main laboratory findings useful for diagnosis are shown in the table 2 .

Muscle enzymes such as creatine phosphokinase (CPK) and lactate dehydrogenase (LDH) may remain raised for more than four months, as occurred in $>90 \%$ of patients affected by T pseudospiralis in Thailand. ${ }^{35}$

CPK isoenzyme profiles are not very helpful. An increased CPK isoenzyme-MB level, generally ascribed to myocardial damage, has been observed in 35\% of trichinellosis patients examined, with no cardiological symptons, suggesting a release of this isoenzyme from other damaged striated muscle cells ${ }^{68} \mathrm{LDH}$ should be evaluated together with CPK, even if the former is less specific. When high levels of CPK and LDH are present, a differential diagnosis with myopathies is necessary. Before antibody levels increase, the level of total serum LDH and the isoenzymatic forms $\mathrm{LD}_{4}$ and $\mathrm{LD}_{5}$ may increase in about $50 \%$ of patients. ${ }^{6}$

Immunoglobulin level changes may also occur, the most characteristic being an increase in total IgE. However, this increase is not a consistent phenomenon and it is better to not exclude trichinellosis by its absence. ${ }^{59}$ A poor correlation with specific IgE has been observed in $T$ spiralis $^{70}$ and $T$ britovi $^{71}$ infections.

\section{Specific findings (immunodiagnosis)}

Many serological tests are available for diagnosis. ${ }^{59}{ }^{60}$ According to Ljungström there are three objectives in immunodiagnosis: (1) recognising the acute infection to allow early anthelminthic treatment, (2) making a retrospective diagnosis, and (3) adding information to the epidemiology of the infection. ${ }^{72}$ Seroconversion usually occurs between the third and fifth week of infection and serum may remain positive up to one year or more after cessation of clinical symptoms. Antibodies have been detected, however, up to 19 years after the end of the acute phase of infection. ${ }^{73}$ Antibody levels do not correlate with the severity of the clinical course ${ }^{69}$ nor with a particular clinical course. ${ }^{74}$

Indirect haemagglutination, bentonite flocculation, indirect immunofluorescence, latex agglutination, and enzyme linked immunosorbent assay (ELISA) are the more commonly used tests, the last being the most sensitive. ${ }^{59}$ Factors such as sensitivity, specifity, convenience, simplicity, cost, and commercial availability must be considered when choosing a test. However, a diagnostic laboratory should have at least two or more tests available to ensure a correct diagnosis: one to detect the response against a soluble antigen and another for antibodies that react with parasite surface antigens. ${ }^{72}$ For the latter, the indirect immunofluorescence test is performed with whole $\mathrm{L}_{1}$ larvae killed with formalin, ${ }^{75}$ or with unfixed frozen sections of infected muscles ${ }^{76}$; the latter is more sensitive. With this test all specific immunoglobulins can be evaluated. In the ELISA method, ${ }^{77}$ excretory-secretory (E/S) antigens are preferable to crude extracts of $T$ spiralis muscle larvae, since they give a higher specificity. This is particularly important in tropical regions where cross reactions with other helminth parasites could give false positive results. ${ }^{78} 79$ Cross reactions with trichinella antigens were observed in patients with autoimmune diseases ${ }^{80}$ It is necessary to standardise as much as possible the antigens used for diagnostic purposes..$^{81} 82$ Recombinant ${ }^{83}$ or synthetic ${ }^{84}$ antigens have been developed. The ELISA can also be used for the evaluation of the different immunoglobulin classes ${ }^{85-87}$ or IgG subclasses ${ }^{88}$ of antibodies, but with a lower sensitivity compared with ELISA IgG. Specific IgM has been detected after 11 years of infection. ${ }^{87}$ The data on specific IgE are contradictory. ${ }^{78}{ }^{86}$ Circulating antigens are also not completely reliable. ${ }^{89}$ They were found in $47 \%$ of 
Table 3 Treatment for intestinal and muscle stages of trichinellosis

\begin{tabular}{ll}
\hline Symptomatic treatment & Specific treatment \\
\hline Analgesic drugs & $\begin{array}{l}\text { Mebendazole } 200-400 \mathrm{mg} \text { three } \\
\text { times/day, followed by } 400 \text { to } 500 \\
\text { mg three times a day for } 10 \text { days }\end{array}$ \\
Antipiretic drugs & $\begin{array}{l}\text { Albendazole } 400 \mathrm{mg} / \text { day for three } \\
\text { days, followed by } 800 \mathrm{mg} / \text { day for } 15 \\
\text { days (is particularly efficient in } T \\
\text { pseudospirais infections) }\end{array}$ \\
$\begin{array}{l}\text { Bed rest } \\
\text { Corticosteroids (prednisolone } \\
\text { at } 50 \mathrm{mg} / \text { day) }\end{array}$ & \begin{tabular}{l} 
Thiabendazole $50 \mathrm{mg} / \mathrm{kg}$ for five days \\
\hline
\end{tabular}
\end{tabular}

From references $98-100$

\section{Key references}

- Murrell KD, Pozio E. Trichinellosis. The zoonosis that won't go quietly. Int J Parasitol 2000;30:1339-49.

- Murrell, KD, Lichtenfels, RJ, Zarlenga, DS, et al. The systematics of the genus Trichinella with a key to the species. Vet Parasitol 2000;93:293-7.

- Murrell KD, Bruschi F. Clinical trichinellosis. In: Sun T, ed. Progress in clinical parasitology. Boca Raton, FL: CRC Press, 1994: 117-50.

- Capo V, Despommier DD. Clinical aspects of infection with Trichinella spp. Clin Microbiol Rev 1996;9:47-54.

- Jonwutiwes S, Chantachum N, Kraivichian P, et al. First outbreak of human trichinellosis caused by Trichinella pseudospiralis. Clin Infect Dis 1998;26:111-15.

- Kociecka W. Trichinellosis: human disease, diagnosis and treatment. Vet Parasitol 2000;93:365-83.

patients with clinical trichinellosis and in 13\% of patients suspected of infection; healthy subjects with no history of trichinellosis were negative. In comparison, the indirect immunofluorescence test and a competitive inhibition assay were more sensitive (100\% positivity for the sera of the above cited patients) ${ }^{89}$ However, the presence of circulating antigens indicates the actual presence of the parasite, eliminating the need for muscle biopsy. Immunoblotting ${ }^{90}{ }^{91}$ can be considered a confirmation test and when E/S antigens are used it is quite specific and useful for follow up studies ${ }^{63}$; however it cannot determinate the species of trichinella responsible for infection. ${ }^{92}$

The analysis of the cellular immune response in humans is of little value at present for diagnosis. ${ }^{87}$

\section{TREATMENT}

It is difficult to differentiate the efficacy of drug treatment from natural recovery of infection in mild to moderate cases. Factors such as the Trichinella species involved, intensity and length of infection, and host response can aid in deciding on the treatment course. ${ }^{3694}$

Light infections do not require treatment. The treatment goal for the very early infection phase is to limit muscle invasion by larvae; when this has already occurred the goal is to reduce muscle damage, which is responsible for the major clinical manifestations. Therapeutic plasma levels of the drug should be maintained for an extended period, rather than high levels for short periods. ${ }^{95}$ The success of treatment is evident from clinical improvement of the patient's symptomatology. In a blinded, placebo controlled trial of antiparasitic drugs for the treatment of myositis during a trichinellosis outbreak (Thailand), mebendazole and thiabendazole were more efficient than placebo or fluconazole; however 30\% of volunteers did not tolerate the side effects of thiabendazole.

\section{Questions (answers on p 22)}

1. Is trichinellosis always derived from the ingestion of undercooked pork containing Trichinella spiralis?

2. Will freezing meat (for example $-15^{\circ} \mathrm{C}$ for 20 days) kill any muscle larvae present?

3. What is neurotrichinosis?

4. What is the cause of myocarditis during trichinellosis?

5. Can the presence of high levels of total IgE help in the diagnosis of trichinellosis?

6. Are eosinophils responsible for the protective response against trichinella?

7. Which factors can modify the clinical course of trichinellosis?

8. Can trichinellosis be lethal?

9. Can a negative muscle biopsy exclude the diagnosis of trichinellosis?

10. Which serological test can be used to confirm the diagnosis of trichinellosis?

The authors did not mention the Trichinella species responsible for infection. ${ }^{96}$ When muscle larvae are already encapsulated drugs such as mebendazole are not able to control infections very well. ${ }^{97}$

In infections caused by $T$ pseudospiralis albendazole $(800$ $\mathrm{mg}$ /day in four doses) is particularly efficient, without apparent side effects ( see table 3 ). ${ }^{35}$

\section{PROGNOSIS}

As already mentioned, the prognosis is usually good with the exceptions of the rare, heavily infected cases. The seroiusness of the infection depends on the number of ingested larvae and on the elapsed time before the diagnosis has been made and treatment begins.

\section{CONCLUSIONS}

The recent occurrence of new Trichinella species, such as $T$ murrelli and $T$ pseudospiralis, in outbreaks in humans, could render the clinical picture of trichinellosis more complicated than when all infections were believed to be caused by T spiralis. Clinicians and infectious disesase specialists should consider this when making diagnosis, since the clinical signs and symptoms may differ, and the therapeutic choices be less clear.

\section{ACKNOWLEDGMENT}

FB was supported by the project Analisi Molecolare, Immunologica E Farmacologica Delle Interazioni Fra Parassiti, Ospiti e Vettori, cofinanced by Italian MURST and by the University of Pisa.

\section{Authors' affiliations}

F Bruschi, Department of Experimental Pathology, University of Pisa, Pisa, Italy

K D Murrell, Danish Center for Experimental Parasitology, Royal

Veterinary and Agricultural University, Frederiksberg, Denmark

\section{REFERENCES}

1 Murrell KD, Pozio E. Trichinellosis: the zoonosis that won't go quietly. Int J Parasitol 2000:30:1339-49.

2 Murrell KD, Lichtenfels RJ, Zarlenga DS, et al. The systematics of the genus trichinella with a key to the species. Vet Parasitol 2000;93:293-7. 3 Pozio E. Factors affecting the flow among domestic, synanthropic and sylvatic cycles of trichinella. Vet Parasitol 2000;93:241-62.

4 Gamble HR, Murrell KD. Detection of parasites in food. Parasitology 1998;1 17:97-11

5 MacLean JP, Viallet J, Law C, et al. Trichinosis in the Canadian Arctic: report of five outbreaks and a new clinical syndrome. J Infect Dis 1989;160:513-20.

6 Viallet J, MacLean JD, Goresky LA, et al. Arctic trichinosis presenting as prolonged diarrhea. Gastroenterology 1986;91:938-46. 
7 Bell RG Generation and expression of Trichinella spiralis immunity. Adv. Parasitol. 1998:41:150-17.

8 Knight PA, Wright SH, Lawrence CE, et al. Delayed expulsion of the nematode Trichinella spiralis in mice lacking the mucosal mast cell-specific granule chymase, mouse mast cell protease-1. J Exp Med 2000; 192: 1849-56

9 Gustowska L, Ruitenberg EJ, Elgersma A, et al. Increase of mucosal mast cells in the jejunum of patients infected with Trichinella spiralis. Int Arch Allergy Appl Immunol 1983;71:304-8.

10 Castro G, Bullick GR. Pathophysiology of the gastrointestinal phase. In: Campbell WC, ed. Trichinella and trichinosis. New York: Plenum Press, 1983: 209-39.

11 Ferraccioli GF, Mercadanti M, Salaffi F, et al. Prospective rheumatological study of muscle and joint symptons during Trichinella nelsoni infection. Q J Med 1988;260:973-84.

12 Katz M, Despommier DD, Gwads RW. Trichinella spiralis. In: Katz M Despommier DD, Gwads RW, eds. Parasitic diseases. New York: Springer-Verlag, 1989: 28-35.

13 Durack DT, Sumi SM, Klebanoff SJ. Neurotoxicity of human eosinophils Proc Natl Acad Sci U S A 1979;76:1443-7.

14 Mawhorter SD, Kazura JW. Trichinosis of the central nervous system. Semin Neurol 1993;13:148-52.

15 Paolocci N, Sironi $M$, Bettini $M$, et al. Immunopathological mechanisms underlying the time course of Trichinella spiralis cardiomyopathy in rats. Virchows Arch 1998;432:261-6.

16 Haig DM, Miller HRP. Differentiation of bone marrow cells into effector cells. In: Behnke JM, ed. Parasites: immunity and pathology. London: Taylor and Francis, 1990: 42-62.

17 Warren KS, Karp R, Pelley RP, et al. The eosinophil stimulation promoter test in murine and human Trichinella spiralis infection. J Infect Dis 1976;134:277-80

18 Finkelman FD, Shea-Donohue T, Goldhill J, et al. Cytokine regulation of host defense against parasitic gastrointestinal nematodes. Lessons from studies with rodent models. Annu Rev Immunol 1997; 15:505-33.

19 Gon S, Saito S, Takeda Y, et al. Apoptosis and in vivo distribution and clearance of eosinophils in normal and Trichinella spiralis-infected rats. $J$ Leukocyte Biol 1997; 62:309-17.

20 Dessein AJ, Parker WL, James SL, et al. IgE antibody and resistance to infection. I. Selective suppression of the $\lg E$ antibody response in rats diminishes the resistance and the eosinophil response to trichinella infection. J Exp Med 1981;153:423-36

21 Watanabe N, Katakura K, Kabayashi A, et al. Protective immunity and eosinophilia in lgE-deficient SJA/9 mice infected with Nippostrongylus brasiliensis and Trichinella spiralis. Proc Natl Acad Sci U S A 1988;85:4460-2.

22 Kazura JW. Immunology of Trichinella spiralis infection. In: Cohen S, Warren $\mathrm{K}$, eds. Immunity to parasitic infections. Oxford: Blackwell, 1982: 654-75.

23 Gansmüller A, Anteunis A, Venturiello SM, et al. Antibody-dependent "in vitro" cytotoxicity of newborn Trichinella spiralis larvae. Nature of the cells involved. Parasite Immunol 1987;9:281-92.

24 Kazura JW. Host defense mechanisms against nematode parasites: destruction of newborn Trichinella spiralis larvae by human antibodies and granulocytes. J Infect Dis 1981;143:712-18.

25 Venturiello SM, Giambartolomei GH, Costantino SN. Immune killing of newborn trichinella larvae by human leukocytes. Parasite Immunol 1993;15:559-64.

26 Wassom DL, Gleich GJ. Damage to Trichinella spiralis newborn larvae by eosinophil major basic protein. Am J Trop Med Hyg 1979:28:860-2.

27 Ruitemberg EJ. Killing of newborn larvae of Trichinella spiralis by eosinophil peroxidase in vitro. Eur J Immunol 1981;1 1:843-5.

28 Bass DA, Szejda P. Mechanisms of killing of newborn larvae of Trichinella spiralis by neutrophils and eosinophils. Killing by generators of hydrogen peroxide in vitro. J Clin Invest 1979;64:1558-64.

29 Herndon FJ, Kayes SG. Depletion of eosinophils by IL-5 monoclonal antibody treatment of mice infected with Trichinella spiralis does not alter parasite burden or immunologic resistance to reinfection. J Immunol 1992; 149:3642-7

30 Vallance BA, Blennerhassett PA, Deng Y, et al. IL-5 contributes to worm expulsion and muscle hypercontractility in a primary $T$ spiralis infection. Am J Physiol 1999;277:G400-8.

31 Hokibara S, Takamoto M, Tominaga A, et al. Marked eosinophilia in interleukin-5 transgenic mice fails to prevent Trichinella spiralis infection. $J$ Parasitol 1997 83:1 186-9.

32 Vallance BA, Matthaei KI, Sanovic S, et al. Interleukin-5 deficient mice exhibit impaired host defence against challenge Trichinella spiralis infections. Parasite Immunol 2000;22:487-92.

33 Stewart GL. Biological and immunological characteristics of Trichinella pseudospiralis. Parasitol Today1989;5:344-9.

34 Stewart GL, Mann MA, Ubelaker JE, et al. A role for elevated plasma corticosterone in modulation of host response during infection with Trichinella pseudospiralis. Parasite Immunol 1988;10:139-50.

35 Jonwutiwes S, Chantachum N, Kraivichian P, et al. First outbreak of human trichinellosis caused by Trichinella pseudospiralis. Clin Infect Dis 1998;26:111-5.

36 Pawlowski ZS. Clinical aspects in man. In: Campbell WC, ed. Trichinella and trichinosis. New York: Plenum Press, 1983: 367-01.

37 Doby JM, Couatarmanac'h A, Campion JP, et al. Trichinose humaine et immuno-depression. Un cas chez un greffé renal. Med Mal Infect 1984;14:293-8

38 Bell RG. T spiralis: differences between "early" and "late" rapid expulsion evident from inhibition studies using cortisone and irradiation. Exp Parasitol 1987;64:385-92.
39 Capo V Despommier DD. Clinical aspects of infection with Trichinella spp. Clin Microbiol Rev 1996;9:47-54.

40 Kassur B, Januszkiewicz J, Poznanska H. Clinic of trichinellosis. In: Kim CW, Pawlowski ZS, eds. Trichinellosis. Hanover, NH: University Press of New England, 1978: 27-44

41 Tassi C, Pozio E, Pelliccia D, et al. Evaluation of some immunological parameters in trichinellosis patients with periorbital edema. Clin Chem Enzymol Comms 1991;4:1-7.

42 Dupouy-Camet J. Caractéres parasitologiques, pathogéniques, antigéniques, isoenzymatiques et génomiques de deux isolats de Trichinella d'origine équine. PhD Thesis. University Paris XII Val de Marne, Paris, France, 1993: 177

43 Aldrige FC. An outbreak of trichinosis in Pennsylvania. Am J Med Sci $1931 ; 181: 312-23$

44 Compton SJ, Celum LC, Thompson D, et al. Trichinosis with ventilatory failure and persistent myocarditis. Clin Infect Dis 1993;16:500-4

45 Gould SE. Clinical manifestations, a. symptomatology. In: Gould SE, ed. Trichinosis in man and animals. Springfield, IL: Charles C Thomas, 1970 269-06.

46 Kramer MD, Aita JF. Trichinosis. In: Vinken BJ, Bruyn GW, eds. Infections of the central nervous system. Vol 35. Handbook of clinical neurology. Amsterdam, North Holland, 1978: 267-90.

47 Dalessio DJ, Wolff HG. Trichinella spiralis infection of the central nervous system. Arch Neurol 1961;4:407-17.

48 Ursell PC, Habib A, Babchick O, et al. Myocarditis caused by Trichinella spiralis. Arch Pathol Lab Med 1984;108:4-5.

49 Gerwel C, Kociecka W, Pawlowski Z. Parasitologic examination of muscles several years after trichinosis. Epidemiol Rev 1970; 24:262-9.

50 Pozio E, La Rosa G, Rossi P, et al. Biological characterizations of trichinella isolates from various host species and geographical regions. J Parasitol 1992;78:647-53.

51 Fröscher W, Gullotta F, Saathoff M, et al. Chronic trichinosis. Clinical bioptic, serological and electromyographic observations. Eur Neurol 1988;28:221-6

52 Kassur B, Januskiewicz J, Poznanska H. Controversial aspects in human trichinellosis. In: Kim CW, Ruitemberg EJ, Teppema JS, eds. Trichinellosis. Chertsey: Reedbooks, 1981: 245-7.

53 Feldmeier $H$, Biensle $U$, Janssen-Rosseck $R$, et al. Sequelae after infection with Trichinella spiralis: a prospective cohort study. Wien Klin Wochenschr 1991;103:111-6.

54 Harms GP, Binz H, Feldmeier K, et al. Trichinosis: a prospective controlled study of patients 10 years after acute infection. Clin Infect Dis 1993;17:637-43.

55 Moorhead A, Grunewald PE, Dietz VJ, et al. Trichinellosis in the United States, 1991-1996: declining but not gone. Am J Trop Med Hyg 1999;60:66-9

56 Kociecka W. Pathophysiological aspects of trichinella infection in man. Ann Ist Super Sanità 1989:25:635-40.

57 Kociekca W, Kaczmarek J, Stachowski B. Electromyographic studies in persons with trichinellosis hystory. Wiad Parazytol 1975;21:721-30.

58 Gould SE. Anatomic pathology. In: Gould SE, ed. Trichinosis in man and animals. Springfield, IL: Charles C Thomas, 1970: 147-89.

59 Murrell KD, Bruschi F. Clinical trichinellosis. In: Sun T, ed. Progress in clinical parasitology. Boca Raton, FL: CRC Press, 1994: 117-50.

60 Despommier DD. Trichinellosis. In: Walls KW, Schantz PM, eds. Immunodiagnosis of parasitic diseases. Vol 1. Helminthic diseases. New York: Academic Press, 1986: 163-81.

61 Stewart GL, Kennedy RR, Larsen E. Alterations in the longevity and fecundity of adult Trichinella pseudospiralis related to the method of isolation of infective larvae. J Parasitol 1990:76:297-01.

62 Bandi C, La Rosa G, Bardin MG, et al. Random amplified polymorphic DNA fingerprints of the eigth taxa of trichinella and their comparison with allozyme analysis. Parasitology 1995;1 10:401-7

63 Andrews JRH, Bandi C, Pozio E, et al. Identification of Trichinella pseudospiralis from a human case using random amplified polymorphic DNA. Am J Trop Med Hyg 1995;53:185-8.

64 Weatherly NF. Anatomical pathology. In: Campbell WC, ed. Trichinella and trichinosis. New York: Plenum Press, 1983:173-8.

65 Gutierrez Y. Trichinelloidea: trichuris, trichinella and capillaria-diocto-phymatoidea: dioctophyme. In: Gutierrez Y, ed. Diagnostic pathology of parasitic infections with clinical correlations. Philadelphia: Lea and Febiger, 1990: 336-50.

66 Ellrodt A, Halfon P, Le Bras P, et al. Multifocal central nervous system lesions on three patients with trichinosis. Arch Neurol 1987;44:432-4.

67 Rycsak M, Sober WA, Kandora TF, et al. Difficulties in diagnosing trichinella encephalitis. Am J Trop Med Hyg 1987;36:573-5.

68 Tassi C, Materazzi L, Pozio E, et al. Creatine kinase isoenzymes in human trichinellosis. Clin Chim Acta 1995;239:197-02.

69 Boczon K, Winiecka W, Kociecka W, et al. The diagnostic value of enzymatic and immunological test in human trichinellosis. Tropenmed Parasitol 1981;32:109-14.

70 Patterson R, Roberts M, Slonka G, et al. Studies of immunoglobulins, bentonite flocculation and $\lg E, \lg G$ and $\lg M$ antibodies in serum from patients with trichinosis. Am J Med 1975;58:787-93.

71 Tassi C, Sparvoli N, Bruschi F. Specific and total IgE in human trichinellosis infection. Use of an amplified ELISA system. Clin Chem Enzymol Comms 1990;3:81-8.

72 Ljungström I. Immunodiagnosis in man. In: Campbell WC, ed. Trichinella and trichinosis. New York: Plenum Press, 1983: 403-24.

73 Kozar Z, Kozar M. Dynamics and persistence of antibodies in trichinellosis. Wiad Parazytol 1968;14:171-85.

74 Dupouy-Camet J, van Knapen F, Ancelle T, et al. Etude des immunoglobulines specifiques (totales, $\lg G, \lg M, \lg A, \lg E$ ) en 
immunofluorescence indirecte et en EUSA chez quarante malades trichinés suivis pendant neuf mois. Pathol Biol (Paris) 1988;36:803-7.

75 Brzosko W, Gancarz Z, Nowoslawski A. Immunofluorescence in the serological diagnosis of Trichinella spiralis infection. Exp Med Microbiol $1965 \cdot 17: 355-65$.

76 Liungström I. Antibody response to Trichinella spiralis. In: Kim C, ed. Trichinellosis. New York: Intext, 1974: 449-60.

77 Engvall E, Liungström I. Detection of human antibodies to Trichinella spiralis by enzyme-linked immunosorbent assay (ELISA). Acta Pathol Microbiol Scand 1975:83:231-7.

78 Au ACS, Ko RC, Simon JW, et al. Study of acute trichinosis in Ghurkas: specificity and sensitivity of enzyme-linked immunosorbent assay for $\lg M$ and $\lg E$ antibodies to trichinella larvae antigens in diagnosis. Trans $R$ Soc Trop Med Hyg 1983;77:412-5.

79 Mahannop P. Setasuban P. Mokarote N, et al. Immunodiagnosis of human trichinellosis and identification of specific antigen for Trichinella spiralis. Int J Parasitol 1995;25:87-94

80 Robert F, Well B, Kassis N, et al. Investigation of immunofluorescence cross-reaction against Trichinella spiralis by Western blot (immunoblot) analysis. Clin Diagn Lab Immunol 1996:3:575-7.

81 Bruschi F, van Knapen F. Workshop on characterization and standardization of trichinella antigens. In: Campbell WC, Pozio E, Bruschi F, eds. Trichinellosis. Rome: Istituto Superiore di Sanità Press, 1994: 627-8.

82 Ortega-Pierres MG, Ypez-Mulia L, Homan W, et al. Workshop on a detailed characterization of Trichinella spiralis antigens. A platform for future studies on antigens and antibodies to this parasite. Parasite Immunol 1996;18:273-84.

83 Zarlenga D, Gamble HR. Molecular cloning and expression of an immunodominant 53-Kda excretory-secretory antigen from Trichinella spiralis muscle larvae. Mol Biochem Parasitol 1990;42:165-74.

84 Bruschi F, Moretti A, Wassom D, et al. Use of a synthetic antigen for the serological diagnosis of human trichinellosis. Parasite 2001;8:S141-3.

85 van Knapen F, Franchimont JH, Verdonk AR, et al. Detection of specific immunoglobulins ( $\lg G, \lg M, \lg A, \lg E$ ) and total $\lg E$ levels in human trichinosis by means of the enzyme-linked immunosorbent assay (ELISA). Am J Trop Med Hyg 1982;31:973-6.

86 Bruschi F, Tassi C, Pozio E. Parasite-specific antibody response in Trichinella sp 3 human infection: a one year follow up. Am J Trop Med Hyg 1990;43:186-93

87 Marinculic A, Lucinger S, Milas J, et al. Persistence of immune response in patients chronically affected by trichinellosis. In: Campbell WC, Pozio E, Bruschi F, eds. Trichinellosis. Rome: Istituto Superiore di Sanità Press, 1994: 347-51.

88 Ljungström I, Hammarström L, Kociecka W, et al. The sequential appearence of $\lg G$ subclasses and lgE during the course of Trichinella spiralis infection. Clin Exp Immunol 1988;74:230-5

89 Ivanoska D, Cuperlovic K, Gamble HR, et al. Comparative efficacy of antigen and antibody detection tests for human trichinellosis. J Parasitol 1989:75:38-41.

90 Dupouy-Camet J, Bougnoux RE, Ancelle T, et al. Antigenic characteristics of two strains of Trichinella spiralis isolated during the horsemeat-related outbreaks of 1985 in France. Parasitol Res 1988;75:79-80

91 Pozio E, Varese P, Gomez Morales MA, et al. Comparison of human trichinellosis caused by Trichinella spiralis and Trichinella britovi. Am J Trop Med Hyg 1993;48:568-75.

92 Ranque $S$, Faugère $B$, Pozio $E$, et al. Trichinella pseudospiralis outbreak in France. Em Infect Dis 2000;6:543-7.

93 Gomez-Morales MA Urbani F, Ausiello CM et al. Proliferation of human peripheral blood mononuclear cells induced by Trichinella spiralis and Trichinella britovi antigens. In: Campbell WC, Pozio E, Bruschi F, eds. Trichinellosis. Rome: Istituto Superiore di Sanità Press, 1994 231-4.

94 Kociecka W. Trichinellosis: human disease, diagnosis and treatment. Vet Parasitol 2000;93:365-83.

95 Campbell WC. Meatborne helminth infections: trichinellosis. In: Hui SY Murrell KD, eds. Food borne disease handbook. Vol 2. New York: Marcel Dekker, 1994: 255-77.

96 Watt G, Saisorn S, Jongsakul K, et al. Blinded, placebo-controlled trial of antiparasitic drugs for trichinosis myositis. J Infect Dis 2000;182:371-4.

97 Pozio E, Sacchini D, Sacchi L, et al. Failure of mebendazole in the treatment of humans with Trichinella spiralis infection at the stage of encapsulated larvae. Clin Infect Dis 2001;32:638-42.

98 Anonymous. Drugs for parasitic infections. Med Lett Drug Ther 1998:40:1-5.
99 Gapinath R, Keystone JS. Trichinosis, In: Rakel RE, ed. Conn's current therapy. Philadelphia: WB Saunders, 1995: 133-4.

100 Fourestiè V, Bougnoux ME, Ancelle T, et al. Randomized trial of albendazole versus thiabendazole plus flubendazole during an outbreak of human trichinellosis. In: Tanner CE, Martinez-Fernandez AR Bolas-Fernandez F, eds. Trichinellosis. Madrid: CSIC Press, 1989: 366-9.

101 Bruschi F, Venturiello SM, Ambrogi F, et al. Eosinofili ed eosinofilia in immunoparassitologia. Immunol Clin Sper 1983;2:93-04.

Answers

1. No, human infections have resulted from ingestion of many kinds of meat in addition to pork. In Europe, for example, over the past 20 years, thousands of cases have resulted from improperly cooked horse meat, wild boars, and even dog meat. All seven species of trichinella have been involved in outbreaks, although most pork derived cases involve $T$ spiralis.

2. Generally, such freezing is effective. However, wild game meat from the arctic and subarctic regions may contain $T$ nativa, which is highly resistant to freezing. In these regions, such meat should be cooked well.

3. This term is used to indicate the involvement, possibly with clinical manifestations, of the central nervous system during infection caused by the parasitic nematode of trichinella genus.

4. We have to distinguish the early phase of infection when migrating larvae may play a relevant part by attempts to invade myocardial muscle and the late phase when immunopathological processes cause a myocardium damage. $5 \mathrm{As}$ in other helminthic infections, total lgE levels may be increased. However, trichinellosis cannot be excluded even when $\lg \mathrm{E}$ is at normal levels. Furthermore, anamnestic, clinical, and serological data are necessary to make diagnosis of infection.

6. Despite the great amount of research using "in vitro" experiments, which showed the ability of these cells to kill parasites in ADCC systems, experiments using both transgenic and knock-out mice for IL-5 have clearly shown that eosinophils play little, if any, part in the immune defence against a primary infection with this parasite.

7. As observed in $T$ britovi and $T$ pseudospiralis outbreaks, the species of trichinella involved, as well as the number of parasites ingested, are quite important factors. However, host characteristics, such as sex, age, and immune status may also be important determinants of clinical outcome.

8. Death due to trichinellosis is rare, thanks to improving of diagnostic aids and the availability of proper treatments, however when a large number of parasites are ingested or the diagnosis is not made quickly, fatal cases can still occur. 9. Muscle biopsy is at present the best way to make a diagnosis when parasites are present, however in cases of very low infections it is possible that parasites are absent in the tissue fragment obtained. In this case a specific and sensitive serological test is valuable in the diagnosis.

10. After an initial serological diagnosis, usually by an ELISA or an immunofluorescence assay, the use of a test such as immunoblot can be useful to confirm the diagnosis. 